\title{
A Guerra Civil Espanhola narrada pelos vencidos: George Orwell e soldados voluntários brasileiros
}

\author{
Maria Cristina Ferreira dos Santos*
}

ymarial@hotmail.com

\section{Resumo}

A Guerra Civil Espanhola é um tema bastante instigante para historiadores e literatos, pois determinou uma época, mudou percursos e visões de mundo, além de ser material de base para a produção de inúmeros relatos, romances, obras de arte, produções cinematográficas, entre outros. O lado vencedor não foi o que contemplou soldados voluntários oriundos de distintos países, porém, a singularidade memorialista acerca deste conflito é queas produções abordam, na grande maioria das vezes, o lado dos vencidos. Nesta perspectiva, pretende-se, neste artigo, enaltecer a obra Lutando na Espanha e recordando a Guerra Civil, de George Orwell, o qual foi soldado voluntário no conflito ao lado dos republicanos, e a coletânea de narrativas orais de exsoldados brasileiros, denominada A revolução possível: História oral de soldados brasileiros na Guerra Civil Espanhola, organizada por José Sebe Bom Meihy. Pretende-se, dessa forma, mostrar que a História é constituída por distintas vozes, as quais fazem parte tanto do lado vencido de um conflito, como do lado vencedor.

\section{Palavras-chave}

Guerra Civil Espanhola; narradores; História

The Spanish Civil War narrated by losers: George Orwell and Brazilian volunteer soldiers

\begin{abstract}
The Spanish Civil War is a very exciting subject for historians and writers, as it has determined a time, changed paths and worldviews, as well as being the basic material for the production of countless reports, novels, works of art, cinematographic productions, among others. The winning side was not the one that contemplated volunteer soldiers from different countries, but the singularity of the memorialist about this conflict is that the productions deal, in the great majority of cases, the side of the vanquished. In this perspective, it is intended, in this article, to praise the work Fighting in Spain and recalling the Civil War, by George Orwell, who was a volunteer soldier in the conflict with the Republicans, and the collection of oral narratives of former Brazilian soldiers, The Possible Revolution: Oral History of Brazilian Soldiers in the Spanish Civil War, organized by José Sebe Bom Meihy. In this way, we intend to show that history is constituted by distinct voices, which are part of both the defeated side of a conflict and the winning side.
\end{abstract}

\section{Keywords}

Spanish Civil War; narrators; History 
Como será escrita a História da

Guerra Civil Espanhola?

(George Orwell)

\section{Introdução}

No final da década de trinta do século XX, a Espanha vivia um paradoxo em diversos segmentos, a saber: aristocracia rural e intuito de industrialização, alvorecer do capitalismo e ideias socialistas, regime liberal e ameaça de ditadura militar, feudalismo anacrônico e modernização. Nesse ínterim, surgiram diversos movimentos em prol da modernização, bem como ideais contra a ameaça da instauração de uma ditadura que obscureceria o país. Esses dilemas foram resultado do declínio da aristocracia rural, bem como o fim da era de colonização e exploração, na medida em que diversas colônias já haviam conquistado a independência, não mais suprindo as necessidades alimentares das grandes potências. Segundo José Carlos Sebe Bom Meihy e Claudio Bertolli Filho (1996):

Na segunda metade do século XIX, a Espanha havia perdido todo o imenso território colonial. Como uma parcela considerável do ouro, da prata e das mercadorias que sustentavam o Estado espanhol era fruto da exploração colonial, a independência das colônias fez com que a antiga metrópole caísse em profunda miséria. A crise econômica trouxe a alta dos preços dos alimentos, a fome e graves epidemias, que abateram ainda mais o ânimo dos antigos colonizadores. O golpe fatal no império espanhol deuse em 1898, quando a Espanha perdeu suas últimas colonias: Cuba e Porto Rico, no Caribe, e as Filipinas, no oceano Pacifico. (MEIHY, FILHO, 1996, p. 9)

O mundo se modernizava, não havendo mais espaço para antigos paradigmas latifundiários que os detentores do poder da Espanha gostariam de perpetuar. O povo vivia na miséria, e os distintos ideais se con- frontavam. Adiciona-se a isso e temos a influência de potências como Alemanha e Itália, as quais tinham interesse que a Espanha mantivesse seu povo sob uma ditadura e continuasse os moldes colonialistas e aristocráticos de outrora.

Quando o general Francisco Franco, através de golpe, assume o poder, tentando impor uma ditadura, e recebendo ajuda bélica da Alemanha, foi o estopim para que comunistas, anarquistas, socialistas e todos aqueles que desejavam um governo Liberal se pusessem contrários a Franco e iniciassem, dessa forma, uma das mais sangrentas guerras, a Civil Espanhola.

\section{Os soldados voluntários e seus relatos}

O que tornou a Guerra Civil Espanhola tão importante foi que, em solo espanhol, se lutava por ideais comuns a diversos países, ou seja, a liberdade, a modernização, a melhoria das condições da classe trabalhadora e, especialmente, a aversão ao Totalitarismo. Assim, diversos voluntários, oriundos de distintas nações, foram à Espanha para lutar ao lado dos republicanos. O lado ditatorial tinha ajuda bélica da Alemanha e da Itália, o lado liberal recebeu ajuda humana, a saber, trinta e cinco mil voluntários de cinquenta e nove países, inclusive do Brasil. Um desses voluntários foi o escritor inglês George Orwell.

Ele nasceu na Índia, em 1903, sob o nome de Eric Arthur Blair, pertencente a uma família aristocrática em decadência. Logo mudou-se para a Inglaterra, onde foi policial, conviveu com trabalhadores braçais de minas e portos e passou fome em Londres. Autor dos famosos livros A Revolução dos Bichos, de 1945, e 1984, que foi escrito em 1949, ambos críticas tenazes contra a privação da liberdade e contra qualquer manifestação de Totalitarismo. Além disso, foi soldado 
voluntário do POUM (Partido Obrero de Unificación Marxista) na Guerra Civil Espanhola. A partir de suas experiências no conflito, escreveu Homenagem à Catalunha, ora também denominado Lutando na Espanha e recordando a guerra civil, obra que teve sua primeira edição na Inglaterra em 1938, ou seja, enquanto o conflito ainda se desenrolava, não tendo a visão do seu desfecho.

A sua obra é uma alternativa consciente de disputar a memória histórica do fato ao fazer oposição à mídia inglesa do período que o reduzia a simplesmente uma luta contra o Fascismo. Nas páginas da narrativa de Orwell, vemos que ele tem a preocupação em querer legar ao mundo a visão sobre a guerra de quem dela participou diretamente.

Uma vez que a História é formada da miríade de relatos sobre um mesmo acontecimento, torna-se indispensável conhecer o maior número possível deles para, dessa forma, se ter um conhecimento efetivo sobre um capítulo histórico. Para reiterar, temos uma afirmação de Paul Ricoeur (2007):

O discurso histórico deve ser construído em forma de obra; cada obra se insere num ambiente já edificado; as releituras do passado são outras tantas reconstruções, às vezes ao preço de custosas demolições: construir, desconstruir, reconstruir são gestos familiares para o historiador. (RICOEUR, 2007, p. 222)

Na obra de George Orwell, há diversas informações importantes sobre o conflito e que são privilégio de relatos de civis, na grande maioria das vezes, não estando presentes nos documentos oficiais sobre o conflito. Um exemplo é o cotidiano dos soldados, que, além de lutarem contra o Totalitarismo, travavam batalhas diárias contra os piolhos, ratos, escassez de alimentos, higiene, roupas e, principalmente, o frio. Para Orwell, o frio era o maior inimigo: "Para mim a guerra significava projéteis ensurdecedores, fragmentos de aço a espalhar-se para todos os lados. Acima de tudo, representava lama, piolhos, fome e frio. É curioso, mas eu receava muito mais o frio do que o inimigo". (ORWELL, 1986, p. 21)

Podemos ter uma ideia da dinâmica da vida dos soldados através do excerto abaixo:

Comíamos em compridas armações de
mesa, tendo como pratos um vasilhame
permanentemente engordurado, e
bebiamos um negócio horrível chamado
porrón. Um porrón é um tipo de garrafa
com bico fino, do qual espirra um jato de
vinho sempre que é virado, e assim pode-
se beber à distância, sem tocá-la com os
lábios, e passa-la de um a outro usuário.
Entrei em greve e exigi uma caneca, as-
sim que vi o porrón em uso. Para mim,
era demasiada a semelhança entre
aquele objeto e um urinol de doentes,
ainda mais quando cheio de vinho bran-
co. (ORWELL, 1986, p. 8 )

Outro fator enaltecido por Orwell, e que nos ajuda a ter uma visão mais amplasobre a guerra espanhola, é a fragmentação dos partidos, a qual será, mais adiante, uma das causas da derrota dos republicanos. Mesmo o seu partido é visto de forma crítica: "Não estou escrevendo um livro de propaganda, e não pretendo apresentar a milícia POUM como uma coisa ideal. Todo o seu sistema apresentava falhas sérias". (ORWELL, 1986, p. 12)

Um dado deveras chistoso é a crítica que o autor inglês faz à falta de habilidade bélica dos espanhóis, a qual foi, inclusive, o que muitas vezes o salvou de ser atingido: "Os espanhóis são bons em muitas coisas, mas não na guerra. Todos os estrangeiros ficam atônitos diante de sua ineficiência, e acima de tudo por sua impontualidade enlouquecedora". (ORWELL, 1986, p. 13)

George Orwell nos faz pensar num detalhe decisivo para os soldados que talvez nunca atentássemos se 
não lêssemos sua obra, a saber, a falta do sistema cartográfico da Espanha na época em que se desenrolava o conflito:

Ao lado desses problemas com o armamento, havia uma escassez de todos os artigos menores que são necessários numa guerra. Não dispúnhamos de mapas, por exemplo. A Espanha jamais fora inteiramente cartografada, e os únicos mapas detalhados existentes para aquela região eram os velhos mapas militares, quase todos em poder dos fascistas. Não tínhamos telêmetros, telescópios, periscópios ou binóculos, exceto os particulares pertencentes a este ou aquele camarada, e tampouco havia foguetes ou sinais luminosos, alicates para cortar arame farpado, ferramentas de armeiro $e$ pouquíssimo era o material para limpar as armas. (ORWELL, 1986, p. 37)

O lado humano dos soldados é evidenciado na narrativa de Orwell, o qual enfatiza que, na guerra de trincheiras, quase não havia baixas, pois "Quando as trincheiras se acham distanciadas uns quinhentos metros, ninguém é atingido senão por acidente". (ORWELL, 1986, p. 38) E o que mais fascina o narrador é o fato de os soldados serem peões numa grande luta política que poderia ter-se transformado numa revolução, caso as potências e países do lado dos republicanos tivessem cedido mais do que voluntários:

O que aconteceu na Espanha, na verdade, não foi apenas uma guerra civ$i l$, mas o início de uma revolução. É este o fato que a imprensa antifascista tratou de obscurecer. A questão viu-se reduzida a "fascismo versus democracia", e o aspecto revolucionário da coisa toda foi oculto tanto quanto possivel. Na Inglaterra, onde a imprensa se acha mais centralizada e o público é mais facilmente iludido do que em outros paises, apenas duas versões da guerra espanhola mereceram qualquer divulgação: a versão direitista dos patriotas cristãos versus bolchevistas dos quais gotejava o sangue das vítimas, e a versão esquerdista de republicanos cavalheirescos que sufocavam uma rebelião militar. A questão central em jogo foi encoberta. (ORWELL, 1986, p.56)
Duas questões chamam a atenção no excerto acima, a crítica à imprensa contemporânea à guerra, a qual, segundo o autor, encobria informações e escolhia o viés mais cômodo dos acontecimentos, e o fato de o autor afirmar que há versões numa guerra, nas apenas duas, dos dois lados em confronto, mas várias.

Em muitas interpretações sobre a Guerra Civil Espanhola, a destruição de igrejas é relatada unicamente como atitude vândala. Porém, no relato de George Orwell, ele faz uma análise mais acurada:

Alguns dos jornais antifascistas estrangeiros chegaram até à mentira piedosa de fazer de conta que as igrejas só eram atacadas quando utilizadas como fortalezas pelos fascistas. Na verdade, as igrejas foram pilhadas por toda a parte e do modo mais natural, porque sabia-se muitíssimo bem que a Igreja da Espanha fazia parte da quadrilha capitalista. Em seis meses que passei na Espanha vi apenas duas igrejas intatas, e até proximidades de julho de 1937 igreja nenhuma pôde reabrir as portas e celebrar missa ou qualquer atividade, com exceção de uma ou duas igrejas protestantes em Madri (ORWELL, 1986, p. 57).

Em relação às versões de um mesmo conflito, Orwell destaca sua crença de que os que têm direito a ter uma posição sobre a guerra deveriam ser os diretamente envolvidos, pois: "Um dos traços mais horríveis da guerra é que toda a propaganda guerreira, todos os gritos e mentiras e ódio, vêm invariavelmente de pessoas que não estão lutando. [...] As pessoas que escreviam panfletos contra nós e nos vilipendiavam nos jornais ficavam, todas elas, bem seguras em suas casas". (ORWELL, 1986, p. 69)

E, com isso, o autor aprendeu que dos dois lados do conflito há mentira e distorção de ideais: "Um dos mais tristes efeitos desta guerra foi ensinar-me que a imprensa esquerdista é tão falsa e desonesta quanto a da direita." (ORWELL, 1986, p.70) 
É curioso que Orwell, à medida que escreveu seu relato, entrementes a guerra se desenrolava, tem uma perspectiva pusilânime, pois ora acredita estar determinando a História, ora não, como vemos em duas de suas reflexões: "Quando se toma parte em acontecimentos assim está-se ao menos um pouco, a meu ver, fazendo história, e por todos os títulos devíamos sentirnos como personagens históricos". (ORWELL, 1986, p.148) E logo mais adiante, ele declara: "Se aquilo era história, não parecia. Afigurava-se mais a um período ruim no front, quando havia falta de homens e tínhamos de fazer turnos prolongados de serviço". (ORWELL, 1986, p. 149)

Titubear sobre suas convicções acerca de um capítulo histórico decisivo enquanto ele ocorre é extremamente normal e contribui para formar o legado do conflito. Esse raciocínio vai de encontro a um pensamento de Martin Heidegger, em que ele afirma:

O que tem história encontra-se inserido num devir. O seu desenvolvimento pode ser ora ascensão, ora queda. O que, desse modo, tem uma história, pode, ao mesmo tempo, fazer história. É fazendo época que, no presente, se determina um futuro. História significa, aqui, um "conjunto de acontecimentos e influências que atravessa passado, presente e futuro". Aqui, o passado não tem primazia. (HEIDEGGER, 2002, p.184)

Em outra declaração, evidentemente equivocada mas compreensível pela proximidade temporal em que ele se encontrava do período, George Orwell insiste no fato de que "Jamais se poderá obter um relato inteiramente preciso e imparcial sobre as lutas em Barcelona, porque não existem os dados necessários. Os futuros historiadores nada terão em que basear-se, exceto um amontoado de acusações e propaganda partidária". (ORWELL, 1986, p. 159) Os historiadores tiveram e têm muito material para formar a Memória Cultural da Guerra Civil Espanhola.
Conforme Aleida Assmann (2011), a Memória

Cultural de um período, ou de um conflito, é constituída das mais diversas visões, de relatos, objetos, descobertas arqueológicas que podem mudar todo o panorama interpretativo, e assim por diante. Há vasta bibliografia sobre o conflito espanhol, diversos filmes, obras de ficção, obras plásticas, documentários, entre outros. Mas temos consciência de que, como afirma Heidegger (2002), a História está sempre sendo construída e aprimorada. Podemos perceber isso ao comparar o relato de George Orwell, que o escreveu em 1936 e o publicou em 1937, ou seja, antes da finalização da guerra civil, e os relatos de soldados brasileiros que sobreviveram ao conflito e deram entrevistas sobre ele muitos anos depois.

José Carlos Sebe Bom Meihy entrevistou cinco sobreviventes entre os soldados brasileiros que participaram da Guerra Civil Espanhola, os quais, impedidos de fazer em seu país a sonhada revolução, abraçaram a oportunidade de lutar na Espanha. O autor inicia expondo os motivos que levaram alguns brasileiros a se alistaram, a saber, a semelhança de alguns problemas espanhóis com os brasileiros. Aqui também se instaurava uma ditadura, a estadonovista, e o povo não mais aceitava os padrões da Velha República.

Em 2008, Meihy entrevistou os cinco voluntários brasileiros, ou seja, mais de setenta anos após o início do conflito. Houve bastante tempo para que os soldados refletissem sobre suas atuações históricas. Carlos Sebe afirma que, apesar da grande bibliografia sobre o conflito espanhol, acerca da participação brasileira na guerra há pouco material: "A literatura sobre o assunto é extremamente rala, titubeante e "ideologizada" em limites tão óbvios que se torna simplista, previsível, unilateral. As contradições internas quase não aparecem e esta ausência revela um mau entendimento do episódio e de sua inserção na história do 
Brasil e latino-americana”. (MEIHY, 2009, p. 39) Dessa forma, ele foi buscar o entendimento da Guerra Civil Espanhola na fonte, ou seja, com aqueles que nela estiveram presentes.

Um dos ex-soldados entrevistados foi José Correia de Sá, o qual se mostrou triste com o descaso que, segundo ele, os historiadores demonstram em relação ao tema, que considera essencial para entender o Brasil de hoje. Oriundo de uma família muito pobre, de mãe viúva, foi criado em orfanato e, quando saiu de lá aos dezoito anos, era a década de trinta do século vinte, em plena crise financeira: "Sentia-me injustiçado pela vida, pelo fato de ter de batalhar tanto por coisas que na realidade deveriam ser direito de todo cidadão. Estou falando da oportunidade de estudar, ter participação social, viver, mesmo que modestamente, com a mãe". (MEIHY, 2009, p. 57)

Depois de muito esforço, José Correia de Sá conseguiu entrar para a escola militar e foi onde teve contato com ideais e notícias do que se passava na Europa. Como é do lado dos vencidos, não nega que já sabia, desde outrora, que os republicanos tinham pouca chance de vitória: "Fui à guerra pensando que meu auxílio poderia causar algumas baixas no exército fascista, e isso bastava. Alguns colegas ficavam ansiosos para voltar porque era uma luta muito desigual, mas eu pensava: Vim combater o nazismo, e vou ser solidário com este povo. Eu adoro o povo espanhol". (MEIHY, 2009, p.73)

De sua longa entrevista, o aspecto mais interessante por ser a análise de um soldado que participou ativamente do conflito, e também por não estar nos livros teóricos sobre a Guerra Civil Espanhola, é a causa da derrota dos republicanos. Conforme José Correia de Sá:

A responsabilidade pela derrota republicana foi das potências capitalistas. Os norte-americanos têm grande culpa por causa do artificio da neutralidade. A não -intervenção nos esmagou. Inclusive eu fui desmilitarizado pela não-intervenção: uma comissão das Nações Unidas, formada por oficiais suecos, veio supervisionar os participantes de países neutros - já no final, é claro - e eles acabaram por desmobilizar a reação. Essa é uma história triste e melancólica. O que é preciso testemunhar é que é um equivoco dizer que as oposições entre as facções de esquerda foram responsáveis pela derrota. Logicamente, as constantes contradições internas influenciaram, mas dai a dizer que elas foram mais responsáveis que os norte-americanos é errado. Afirmar que as quebras da esquerda causaram a perda da guerra equivale a dizer que os norte-americanos não foram os culpados. Não, isso não pode ocorrer sem crítica. (MEIHY, 2009, p. 76)

No excerto acima, vemos o quanto a análise de José Correia de Sá difere de George Orwell quanto aos motivos da derrota, este obviamente influenciado pela proximidade temporal e por ter escrito concomitante ao desenrolar da guerra, e aquele com uma visão mais acurada pela distância diacrônica. Orwell responsabiliza a falta de organização entre as facções do lado republicano pela derrota, José diz que isso também influenciou, mas que a maior causa foi o descaso das potências, a falta de ajuda bélica de países como os Estados Unidos.

Outra informação deveras importante para se constituir a Memória Cultural da Guerra Civil Espanhola fornecida por José Correia de Sá é a de que ele lamenta o fato de não ter logrado anistia, não a política, que conseguiu em 1970, mas a do Exército. Jamais foi reenquadrado às Forças Armadas Brasileiras. E recebe apenas uma pensão como aluno: "Eu poderia estar recebendo bem mais se fosse considerada a patente que recebi de capitão na Guerra Civil Espanhola". (MEIHY, 2009, p. 92)

Outro dos entrevistados foi o militar Apolônio de Carvalho, o qual aponta que, para entendermos a 
conjuntura brasileira da época do conflito espanhol, é preciso reporter-se aos desdobramentos da crise econômica de 1929. Essa crise foi responsável pela efervescência das discrepâncias entre direita e esquerda, especialmente quanto à tomada de consciência sobre os direitos civis.

A mais pertinente observação feita por Apolônio de Carvalho e que, indubitavelmente, não aparece nos registros históricos formais, é a de a que a prisão onde esteve por ter atitudes tidas como comunistas, foi "a primeira grande escola moderna de formação política brasileira" (MEIHY, 2009, p.111). Lá ele aprendeu a experiência de vários grupos revolucionários, o que o ajudou a se definir como militante:

Não há exagero em afirmar que a prisão foi um importante laboratório político, repleto de comunistas, socialistas, nacionalistas. Havia na prisão muitos oficiais, jornalistas, professores, catedráticos das melhores universidades do país. Tínhamos lá conferências, palestras, enfim, verdadeiros cursos. Foi assim que, de maneira mais elaborada, passei a conhecer a vida política do país. Foi por meio dos comunistas que aprendi a ter uma visão da sociedade dividida em classes, o que era a luta de classes e os mecanismos de dominação política e social. (MEIHY, 2009, p. 111)

Além disso, outro dado deveras interessante apontado por Apolônio é, segundo ele, uma página esquecida da História, a saber, o fato de que alguns imigrantes espanhóis, italianos, alemães, romenos e checos também foram à Espanha e lutaram ao lado dos republicanos. Não foram apenas jovens militares brasileiros que almejavam um mundo livre da privação da liberdade que se alistaram, mas também aqueles que haviam fugido da Europa justamente para ficar longe das facetas do Totalitarismo. Alguns para lá voltaram para derrubar o inimigo.
E sobre o cotidiano da guerra, ele declara, reiterando o que já havia mencionado George Orwell, que havia comida suficiente na Espanha para os republicanos, o problema maior era o frio, não a fome: “A literatura da direita pinta um quadro avesso da realidade espanhola. $\mathrm{O}$ exército republicano era bem alimentado. Nós não passávamos a caviar, mas tínhamos comida, éramos bem cuidados, tínhamos roupas e tudo". (MEIHY, 2009, p. 121)

Apolônio reitera o argumentado, já enaltecido por José Correia de Sá, de que a divisão entre as facções da esquerda, ou seja, entre comunistas, anarquistas, socialistas, contribui para a derrota dos republicanos, mas que o fator determinante foi a nãointervenção das grandes potências.

Outro soldado entrevistado foi Delcy Silveira, o qual difere um pouco dos demais por ser oriundo de uma família abastada, pai latifundiário do Rio Grande do Sul. Contudo, era uma família liberal, a qual plantou as sementes idealistas que o levariam a combater em solo espanhol pela liberdade e pelos direitos comuns a todos. Ele foi preso, como os outros soldados, na década de trinta, quando reinava o Estado Novo, devido às suas atitudes antifascistas e anti-imperialistas. Ficou um ano na prisão e, depois de solto, foi exilado. Em terra estrangeira, tomou conhecimento da causa republicana espanhola: "O mesmo fascismo que fundamentava o integralismo, e que estava tão próximo do governo de Getúlio, seria o nosso inimigo na Espanha. Lá, ao menos, a República se levantava contra a opressão e o povo ia à ruas defender sua liberdade. Era nossa obrigação contribuir para a causa espanhola”. (MEIHY, 2009, p. 143)

Uma vez em Portbou, o que mais lhe chamou a atenção, o que mais ficou latente em sua memória e o que mais o traumatizou foi a destruição das cidades e, 
por baixo dos escombros, os cadáveres em decomposição:

Recordo com detalhes os acontecimentos desta etapa. Tudo ficou retido em minha memória como palavras escritas. $\mathrm{Na}$ cidade, os prédios do governo, igrejas, comércio, o centro parecia um deserto: tudo estava destruído. Nós de um lado, eles do outro, entre a gente a ponte destruída. À noite, fazíamos patrulhas. A ronda começava logo que escurecia: três soldados e eu andávamos por certos pontos da cidade. As cenas eram pavorosas. Pavorosas. (MEIHY, 2009, p.148)

Delcy Silveira também reitera a posição dos demais soldados mencionados, a saber, a de que a nãointervenção das potências do lado republicano foi a responsável por tornar o conflito tão sangrento e pela derrota dos esquerdistas:

Os combates na Batalha do Ebro foram os mais sangrentos de todos em que tomei parte. O poderio militar deles era muitas vezes superior aos nossos. Eles tinham a ajuda da Alemanha e da Itália, enquanto nós estávamos encurralados pela França e pela Inglaterra. Um crime! De um lado, a intervenção nazi-fascista, com soldados, equipamentos, armas, etc. Do outro, os países França e Inglaterra, observando a chacina, "neutros". Era o pacto de não-intervenção. (MEIHY, 2009, p. 151)

Outra informação bastante válida fornecida na entrevista de Delcy Silveira e que, segundo ele, pouco explorada e registrada, é que havia muitas deserções das tropas inimigas, ou seja, muitos soldados fascistas, ao longo do conflito, passaram para o lado republicano. E finaliza seu discurso afirmando sua tristeza em ver que, não raras vezes, os soldados são olvidados pela História: "Fico até um pouco surpreso como pessoas com trajetórias de vida tão ricas, tão entranhadas em alguns acontecimentos políticos do Brasil são completamente esquecidas". (MEIHY, 2009, p. 160)
Homero de Castro Jobim foi o outro excombatente entrevistado por José Carlos Sebe Bom Meihy. Sua característica especial é ter composto um diário sobre suas impressões e experiências da Guerra Civil Espanhola, o qual serviu de base ao escritor Erico Verissimo para a criação de seu romance Saga, em que o protagonista é um herói voluntário das Brigadas Internacionais.

Ele enfatiza muito em seu discurso a questão do Levante de 35, do qual participou e que, conforme sua análise, foi um verdadeiro erro histórico, foi o responsável por dar oportunidade a Getúlio Vargas para criar o Estado Novo:

O Levante de 35 não tinha nenhuma condição para dar certo. Foi uma ilusão. Uma ilusão pela qual os comunistas teriam a possiblidade de tomar o governo. Para mim, hoje em dia, acho inacreditável que homens que tinham certa maturidade, que possuiam uma boa formação intelectual, pudessem ter feito uma coisa daquelas. E, 35 foi uma loucura política. (MEIHY, 2009, p.177)

Além disso, corrobora a visão de seus companheiros de que lutar na Espanha foi uma causa universal, foi uma maneira de tentar resolver os problemas brasileiros em solo estrangeiro. Também enfatiza sua tristeza pelo esquecimento de participações tão intensas dos jovens soldados voluntários.

Ademais, como grande erudito, Homero de Castro Jobim demonstra ter uma definição de História semelhante às apontadas acima, como a de Martin Heidegger, pois afirma que o passado não é estanque, está sempre recebendo atualizações: "A distância no tempo anula muitos significados e garante outros sentidos aos mesmos fatos do passado" (MEIHY, 2009, p. 182).

O último ex-soldado voluntário das Brigadas Internacionais entrevistado foi Nelson de Souza Alves, 
de origem humilde. Um dos comentários mais interessantes que ele fez na sua entrevista a José Carlos Sebe Bom Meihy, e que ajuda a enriquecer a Memória Cultural sobre a Guerra Civil Espanhola, é acerca dos portugueses, pois a maioria dos soldados dessa nacionalidade, diferente dos brasileiros, foram à Espanha sem saber que lutariam, ou seja, foram "iludidos" pelo governo português que lá encontrariam trabalho e, uma vez em solo espanhol, foram postos nas Brigadas.

Ele difere dos demais soldados entrevistados por ter ficado até o final do conflito, enquanto os outros lá permaneceram um ano no máximo, mas ele, da Brigada Garibaldi, ficou até 1939. E quanto à derrota dos republicanos, concorda com os demais que a divisão entre os da esquerda foi um dos fatores decisivos, acrescentado um dado novo: que a discórdia era tão grande entre comunistas e anarquistas que houve traições e até fuzilamentos.

No desfecho de seu depoimento, Nelson de Souza Alves rende homenagem às mulheres espanholas, assinalando um fato pouco, ou nada, mencionado quando se fala na Guerra Civil Espanhola, ou seja, o de que as mulheres republicanas, diversas vezes, não só assumiram os trabalhos dos homens que estavam nas frentes, como foram à luta. Para finalizar, questiona-se se valeu a pena a morte de tantas pessoas:

Hoje em dia me pergunto se valeu a pena $o$ sacrificio de quase 1 milhão de vidas. Às vezes, sinceramente, fico na dúvida, posto que assistimos ao ressurgimento do fascismo e do nazismo como se fossem ideologias válidas. Espero que as pessoas, em geral, se conscientizem da ameaça do autoritarismo e das consequências funestas para a sociedade. Os episódios da Espanha demonstraram que sim, que ela foi vermelha pelo sangue de seus filhos e de tantos outros que deram a vida pela causa republicana (MEIHY, 2009, p. 218)

\section{À guisa de conclusões}

Ao redigir este artigo, que teve como escopo primordial valorizar o relato de soldados voluntários do lado dos vencidos, ficava latente em minha memória uns versos de João Cabral de Melo Neto, do poema $\mathrm{Te}$ cendo a manhã:

Um galo sozinho não tece uma manhã: ele precisará sempre de outros galos. De um que apanhe esse grito que ele $e$ o lance a outro; de um outro galo que apanhe o grito de um galo antes $e$ o lance a outro; e de outros galos que com muitos outros galos se cruzem os fios de sol de seus gritos de galo, para que a manhã, desde uma teia tênue, se vá tecendo, entre todos os galos.

Lembrei-me desta estrofe porque não será a História de um episódio a junção de diversos gritos, não será cada voluntário aqui mencionado, e tantos outros que não o foram, metaforicamente como galos cujas vozes se juntam para formar a Memória Cultural que hoje temos da Guerra Civil Espanhola? Cada um contribuiu, à sua maneira, todos com informações genuínas e importantes. Como vimos, há diferenças de um relato escrito entrementes ao conflito e outros feitos décadas depois.

A História continua sendo tecida e cabe a nós, estudiosos, historiadores, literatos, buscar novos gritos, ouvir novas vozes para enriquecê-la, sempre! E, principalmente, para impedir o que tanto entristece os excombatentes, ou seja, o esquecimento de seus legados, o olvido de que foram indivíduos que intensamente mudaram rumos. Como afirma George Orwell: "Dezenas de milhares de indivíduos foram lutar, mas as dezenas de milhões que não o fizeram mantiveram-se apáticas" (ORWELL, 1986, p. 73). Está na hora de impedir essa apatia e deixar vir à tona todas as vozes que vivenciaram um dos maiores conflitos civis de nossa História. 
A GUERRA CIVIL ESPANHOLA NARRADA PELOS VENCIDOS: GEORGE ORWELL E SOLDADOS VOLUNTÁRIOS BRASILEIROS

\section{Referências}

ASSMANN, Aleida. Espaços da recordação: formas e transformações da memória cultural. Tradução de Paulo Soethe. Campinas, SP: Editora da UNICAMP, 2011.

HEIDEGGER, Martin. Ser e tempo. 11 ed. Petrópolis: Vozes, 2002 Parte I.

MEIHY, J.S.B. A revolução possível: História oral de soldados brasileiros na Guerra Civil Espanhola. São Paulo: Xamã, 2009.

. A Guerra Civil Espanhola. São Paulo: Ática, 1996.

ORWELL, George. Lutando na Espanha e recordando a Guerra Civil. Trad. Affonso Blacheye. Porto Alegre: Globo, 1988.

RICOUER, Paul. A memória, a história, o esquecimento. Trad. de Alain Français (et al).Campinas: Editora UNICAMP, 2007.

Submissão: 05/12/2016 Aceite: 05/08/2017 